\begin{tabular}{|c|c|c|c|}
\hline NATAL & $\begin{array}{l}8^{\text {th }} \text { CIDI } \\
8^{\text {th }} \text { Information Design } \\
\text { International Conference }\end{array}$ & $\begin{array}{l}8^{\text {th }} \text { CONGIC } \\
8^{\text {th }} \text { Information Design } \\
\text { Student Conference }\end{array}$ & $\begin{array}{l}\text { Blucher Design Proceedings } \\
\text { Junho } 2018 \text {, num. } 1 \text {, vol. } 4 \\
\text { proceedings.blucher.com.br }\end{array}$ \\
\hline
\end{tabular}

\title{
Relação entre o Design da Informação e a pesquisa com Compósitos Laminados derivados do "Fibrobarro", como meio de interpretação, comunicação e informação para a disseminação e socialização dos conhecimentos sobre essa técnica construtiva.
}

\author{
Relationship between the information Design and research with Laminated \\ Composite derived from the "Fibrobarro", as a means of interpretation, \\ communication and information dissemination and socialization of knowledge of this \\ technique.
}

Ramilo, Vicente Jesus dos Santos ${ }^{1}$, RIPPER, José Luiz Mendes²

Palavras chave: Construção, Barro, Forma, Interpretação, Informação.

O artigo aborda a relação entre a pesquisa com compósitos laminados derivados do "Fibrobarro", desenvolvida no Laboratório de Investigação em Livre Desenho - LILD, do departamento de Artes \& Design da PUC/Rio, e o Design da Informação revelando a importância do material para o Meio Ambiente e sua Sustentabilidade e a influência e a contribuição dessa área do Design na visualização, cognição e informação para disseminação e socialização de conhecimentos sobre essa técnica construtiva. Ao longo da pesquisa, ocorre a interdisciplinaridade entre diferentes áreas do saber, tais como o Design, a Engenharia e a Arquitetura, revelando o entendimento e a comunicação entre elas, colaborando com a função do Designer no desenvolvimento desses materiais, na busca pela melhor solução para problemas construtivos comuns de Design e estruturas de Engenharia Civil, que envolve os pesquisadores do LILD. A metodologia da pesquisa é a do Desenho Social, da Temática Nativa e de modelos, na qual os objetos são desenvolvidos, através de pequenas antecipações e da alternância entre as ideias e as concretizações, referindo-se a uma sistematização dos procedimentos, à medida que os laminados são elaborados com diferentes materiais, sendo os principais, a terra crua, as fibras naturais, o bambu e a resina vegetal. Neste contexto, 0 Design da Informação traz enorme contribuição, disseminando os conhecimentos sobre uso dessa técnica e os processos construtivos utilizados, a partir de diferentes percepções, leituras e interpretações dos objetos construídos, que possibilitam identificar e denominar os domínios semânticos e sintáticos do material, quanto as suas geometrias, expressões físicas e aplicações, conforme destacam MOREIRA e RIPPER (2014), meus principais referenciais. Da leitura do objeto como um texto, priorizo a sua expressão física, para onde convergem todos os conteúdos semânticos de sua competência e mais especificamente o seu uso e funcionalidade, proporcionando ao usuário/leitor a possibilidade de mudança de

Anais do 8 CIDI e 8 CONGIC

Guilherme Santa Rosa; Cristina Portugal (orgs.)

Sociedade Brasileira de Design da Informação - SBDI

Natal | Brasil | 2017

ISBN 978-85-212-1305-5
Proceedings of the $8^{\text {th }} \mathrm{CIDI}$ and $8^{\text {th }}$ CONGIC

Guilherme Santa Rosa; Cristina Portugal (orgs.)

Sociedade Brasileira de Design da Informação - SBD

Natal| Brazil | 2017

ISBN 978-85-212-1305-5 
comportamento e de consciência em relação à sustentabilidade do meio ambiente a partir do uso desses materiais e das informações geradas na pesquisa.

Keywords: Construction, Clay, Form, Interpretation, Information.

The article discusses the relationship between the composite laminate research derived from the "Fibrobarro", developed in the laboratory of research in Free Drawing-LILD, Department of Arts \& PUC/Rio's Design, and the Design of information revealing the importance of the material for the environment and your sustainability and influence and contribution of this area of Design in visualization, cognition and information for dissemination and socialization of knowledge about this technique. Throughout the research, interdisciplinarity between different areas of knowledge, such as Design, engineering and architecture, revealing the understanding and communication between them, collaborating with the Designer's function in the development of these materials, in search for the best solution to problems common in Design and construction of Civil engineering structures, involving researchers from LILD. The research methodology is the Social design of Native-themed and models, in which the objects are developed, through small and anticipations of alternation between the ideas and achievements, referring to a systematization of procedures, as the laminates are made with different materials, being the main, raw land, natural fibers, bamboo and vegetable resin. In this context, the information Design brings enormous contribution, disseminating knowledge about use of this technique and the construction processes used, from different perceptions, readings and interpretations of the constructed objects, that make it possible to identify and name the semantic and syntactic domains of the material, as its physical expressions and applications, geometries, as they emphasize MOREIRA and RIPPER (2014), my main references. Reading the object as a text, prioritize the your physical expression, where converge all semantic content of your competence and more specifically your use and functionality, providing the user/reader the possibility of change in behaviour and awareness in relation to the sustainability of the environment from the use of these materials and the information generated in the search. 


\section{Introdução}

O artigo destaca a relação entre a pesquisa com compósitos laminados, desenvolvida pelo Laboratório de Investigação em Livre Desenho do Departamento de Artes e Design da PUC/Rio - LILD/DAD com o Design da Informação e a influência e contribuição desta área do Design, como mediadora para a percepção, representação e cognição da técnica empregada e da pesquisa como um todo, na interação entre os participantes e usuários e/ou leitores e como meio de comunicação e disseminação desse conhecimento, tomando como base conceitos que nos ajudam a interpretar o material, conforme a sua sintaxe, semântica e pragmática, identificando o seu uso e funcionalidade. Destaca ainda como os compósitos laminados surgiram e como estão sendo desenvolvidos; sua finalidade, como são aplicados no contexto construtivo; as relações dos usuários com o material e a importância deles para o meio ambiente e a sua sustentabilidade.

A questão da sustentabilidade ${ }^{1}$ (HOGAN, 1993), tão discutida nos últimos tempos, ganha ainda mais força quando percebemos que as medidas adotadas para a preservação do meio ambiente, ainda são insuficientes para diminuir os impactos à natureza, causados pelo homem, decorrentes do fenômeno da Metropolização com o crescente processo de urbanização das cidades, a industrialização, consumo desenfreado e descarte de lixo.

O objetivo da pesquisa é o desenvolvimento de compósitos laminados para revestimentos e vedações de estruturas de bambu autoportantes, concebidos com materiais naturais, derivados da técnica do "Fibrobarro", resgatando técnicas vernaculares de construção, tais como a Taipa de Mão, a Taipa de Pilão, o Pau a Pique, o Adobe, entre outras, que contribuam para a diminuição do impacto ambiental e para qualidade de vida dos usuários. A pesquisa está em andamento, através de experimentos e ensaios realizados no LILD e de atividades realizadas na forma de mutirões no laboratório e em comunidades rurais urbanizadas $^{2}$ e da convivência (ILLICH, 1976) com estes grupos, utilizando terra crua, fibras naturais e bambu, contribuindo para o resgate de modos e fazeres e para o aprendizado e repasse desses conhecimentos para gerações futuras. Além de serem facilmente encontrados, custam muito pouco e consomem pouca energia do ponto de vista humano e material.

Figuras 1 e 2: Laminados derivados do "Fibrobarro" feitos com terra crua, sisal e resina de mamona. (RAMILO, V. J. S., 2016).
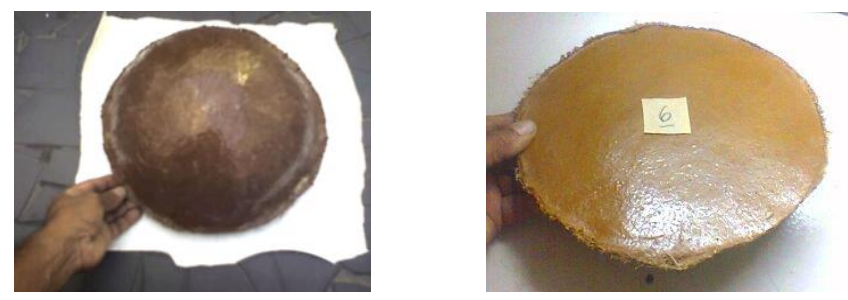


\begin{abstract}
${ }^{1}$ A noção de sustentabilidade implica uma necessária inter-relação entre justiça social, qualidade de vida, equilíbrio ambiental e a necessidade de desenvolvimento com respeito à capacidade de suporte. (HOGAN, 1993)

${ }^{2}$ Comunidades rurais que ao longo do tempo sofreram grande influência da urbanização, mas que ainda mantém algumas tradições, tais como o uso de recursos regionais para a construção de casas e objetos de uso cotidiano. (SANTOS, V. J., 2012)
\end{abstract}

\title{
1.1 Contribuição da pesquisa com Compósitos Laminados para a redução do impacto ambiental
}

O desenvolvimento dos compósitos laminados contribui para a minimização dos problemas construtivos existente entre as áreas de Design, Engenharia e Arquitetura, e para a redução do impacto ambiental e da quantidade de resíduos sólidos descartados pela construção civil, que utilizam materiais convencionais que demandam grandes quantidades de energia, tais como ferro, cimento, pedra, madeira, entre outros. Estimula ainda, a mudança de comportamento do usuário e o aumento da consciência ambiental, trazendo consigo a possibilidade de inserção deste material construtivo em contextos arquitetônicos, como alternativa às construções de alvenaria, contribuindo para a melhoria da qualidade das moradias e para a diminuição do déficit habitacional, tanto em áreas rurais como em áreas urbanas, criando possibilidades de mudanças nas formas arquitetônicas que abusam das linhas retas e formas quadradas. Apesar da massificação do uso de materiais convencionais, as técnicas arquitetônicas tradicionais do meio rural continuam vivas e criando possibilidades e alternativas construtivas mais baratas e acessíveis para as populações mais carentes, que enfrentam dificuldades como falta de moradia, água, saneamento, saúde, transporte, educação, segurança, etc; motivos que nos leva a pensar em desenvolver um material para ser utilizado em processos construtivos, com possibilidades de amenizar, ao menos em ações pontuais, o déficit habitacional e a qualidade das moradias, causados por problemas econômicos e financeiros e pelos desastres naturais e ambientais que acabam por arrasar qualquer plano de vida, tais como os que ocorreram nos municípios de Friburgo e Petrópolis, RJ, em Janeiro de 2011, Angra do Reis, RJ, em Julho de 2013, e recentemente no distrito de Mariana, MG, em Novembro de 2015.

\section{Técnicas construtivas com terra crua e fibras}

O "Fibrobarro" (SANTOS, V. J., 2012) originou-se das técnicas utilizadas pelo homem, através dos tempos, que utilizam a terra crua para construir. Armado com bambu ou através da técnica de moldagem sobre superfícies; encontra-se no LILD em desenvolvimento e constante aperfeiçoamento técnico, através de adaptações, seja em atividades laboratoriais ou em atividades comunitárias, enfatizando a elaboração de uma nova composição a partir das tradicionais técnicas construtivas tradicionais. O "fibrobarro" armado pode ser usado em estruturas muito delgadas, como cascas, e neste caso suas propriedades melhoram, quanto mais fina a espessura da casca. Além de suas propriedades, o seu derivado armado pode descrever diferentes geometrias, sem o auxílio de fôrmas ou moldes. A ossatura da armação principal, no caso do uso do bambu como elemento estrutural, descreve a forma requerida e a argamassa de "fibrobarro" cobre e protege esta armação. Os limites precisos para as construções com "fibrobarro" armado, deverão ser fixados por cálculos de engenharia, ainda 
norteados por modelos e corpos de provas instrumentados. Também a argamassa deve ser estudada em sua micro-estrutura pela engenharia dos materiais.

Em recente revisão bibliográfica, verifiquei que os autores FERREIRA (2015), XAXÁ (2013), PEREIRA, D. A. M.; PEREIRA, M. S.; OLIVEIRA, R. S; MELO e CAVALCANTE (2014), se referem a técnicas construtivas tradicionais vernaculares, que utilizam a terra crua sobre estruturas ou painéis de madeira ou bambu; conhecidas como Taipa de Pilão, Taipa de Sebe, Taipa de Mão, Pau a Pique, Adobe, Barro armado, entre outras. Neste ponto, creio ser pertinente salientar a diferença existente entre "Fibrobarro" e Compósitos Laminados ${ }^{3}$. O "Fibrobarro" surgiu a partir das técnicas tradicionais e conforme os autores citados; verifiquei que em todas elas as fibras são agregadas à terra crua, formando argamassas com espessuras que ultrapassam $10 \mathrm{~cm}$ e são usadas como revestimentos e vedações na forma de argamassa de reboco ou de blocos para levantamento de paredes; enquanto que nos compósitos laminados as espessuras são muito mais finas do que as espessuras encontradas nas técnicas mencionadas, variando entre $0,5 \mathrm{~cm}$ e $5,0 \mathrm{~cm}$, o que thes conferem menor peso, graças à saturação máxima de fibras na argamassa.

\section{LILD: Arquitetura que estimula a criação de objetos e suas interpretações}

O LILD/DAD - PUC/Rio, espaço de trabalho no qual se desenvolve a pesquisa, revela um design muito particular, que recebe grande influência do Design da Informação, estimulando a criação e a interpretação dos objetos feitos com este material e para a disseminação desses conhecimentos.

O LILD nasceu como um laboratório interdisciplinar de Design, Arquitetura e Engenharia, onde são desenvolvidos processos construtivos, voltados para as áreas rurais do interior do Brasil, disseminando tecnologias acessíveis a partir de materiais naturais pouco processados e fica localizado em galpão de aproximadamente $200 \mathrm{~m}^{2}$, onde podemos observar na sua arquitetura a geometria e os tipos de ligações TRIDI 2000, influência arquitetônica de estudiosos em geodésica, tais como Buckminster Fuller e Frei Otto (LOTUFO e LOPES, 1982, p. 56), que permite a entrada da luz do sol, tanto de cima e do centro do galpão, como pelos lados, e que conforme a movimentação do sol; existe uma contínua mudança de aparência dos objetos de estudo, possibilitando diferentes interpretações sobre eles. A partir dessas interpretações, com frequência surgem novas possibilidades construtivas e de uso dos objetos, conforme a condições mencionadas.

Figuras 3 e 4: Arquitetura do LILD influenciada por Buckminster Fuller. (WWW.Coroflot.com/LILD)
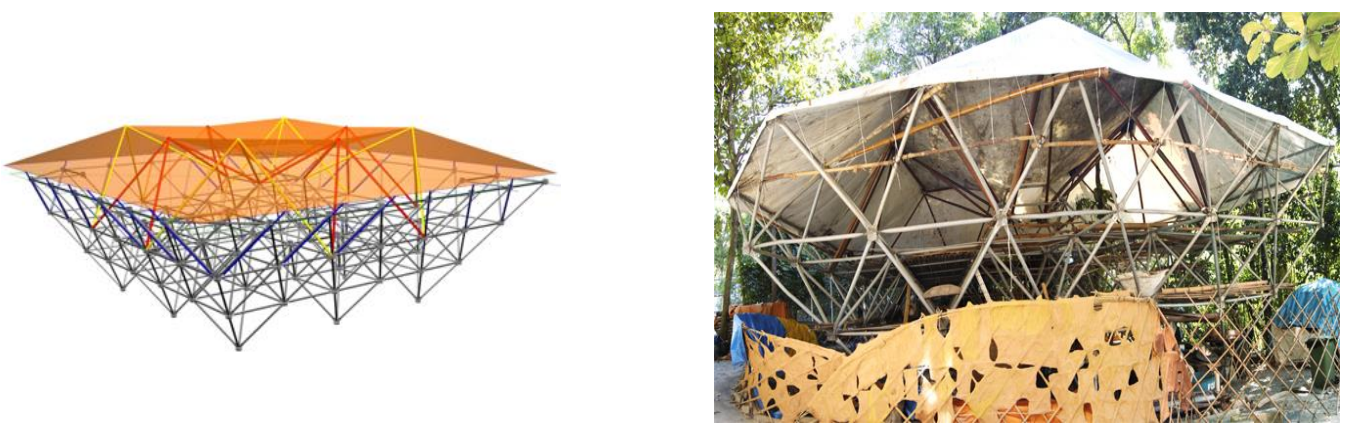


\begin{abstract}
${ }^{3}$ MORAIS, (1997, p. 25). Compósitos laminados são um grupo muito particular de um conjunto de materiais que se designam por compósitos, constituídos por uma matriz que aglomera um reforço. Distinguem-se diversos tipos quanto à natureza do reforço (fibras longas, fibras curtas, partículas, etc.), matriz (polimérica, metálica, cerâmica, etc.), processo de fabrico, entre outros.
\end{abstract}

\title{
4 A Metodologia adotada para a obtenção dos compósitos laminados
}

A metodologia empregada no LILD se dá através de uma atividade projetiva e teórica e é produto de um gestual técnico que inclui movimentos precisos ajustados ao material, acrescentando-se a elas a metodologia dos modelos que contribui para a concretização de objetos por meio de modelos físicos, em tamanho reduzido e em escala, para que sejam trabalhados, evitando-se miniaturizações dos componentes, RIPPER et al (1999). Tal como acontece com os objetos que são produzidos no laboratório, a pesquisa com laminados se desenvolve aos poucos, feita em pequenas antecipações e da alternância entre as ideias e as concretizações, ou seja, por aproximações sucessivas.

\section{Processo de obtenção de compósitos laminados a partir do "Fibrobarro"}

Os compósitos laminados são obtidos em experimentos e ensaios, nos quais são utilizadas as técnicas tradicionais para concepção do material que servirá como revestimento e vedação. Em geral os materiais são misturados, com as mãos ou pisoteio, individualmente ou no regime de mutirão, até que se obtenha uma massa homogênea e consistente, pronta para ser aplicada em estruturas de bambu ou moldada sobre superfícies.

Figuras 5, 6 e 7: Massa de barro saturada com fibras de sisal. (SANTOS, V. J., 2012)
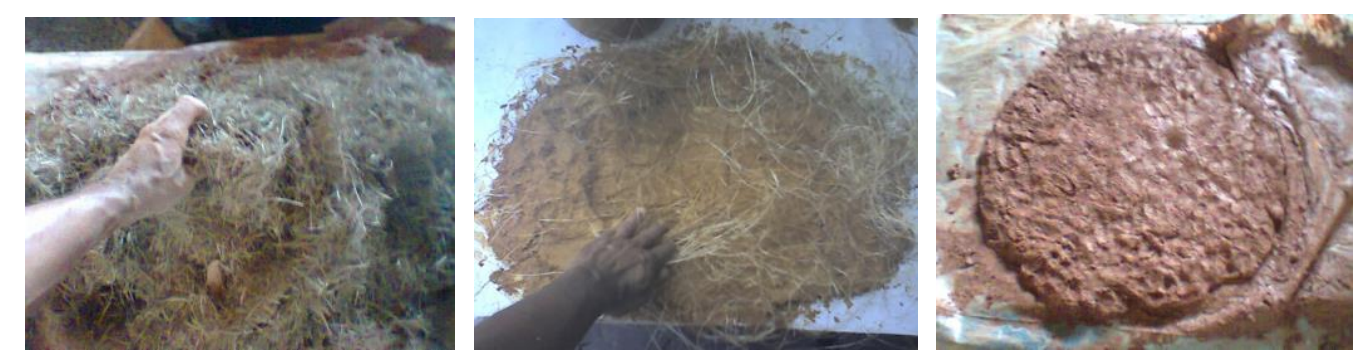

A massa também pode ser trabalhada com a ajuda de colheres de pedreiro e espátulas, quando houver necessidade de ser ajustada em moldes, conforme as espessuras desejadas.

Figuras 8, 9, 10: Massa ajustada conforme a espessura desejada (RAMILO, V. J. S., 2017)
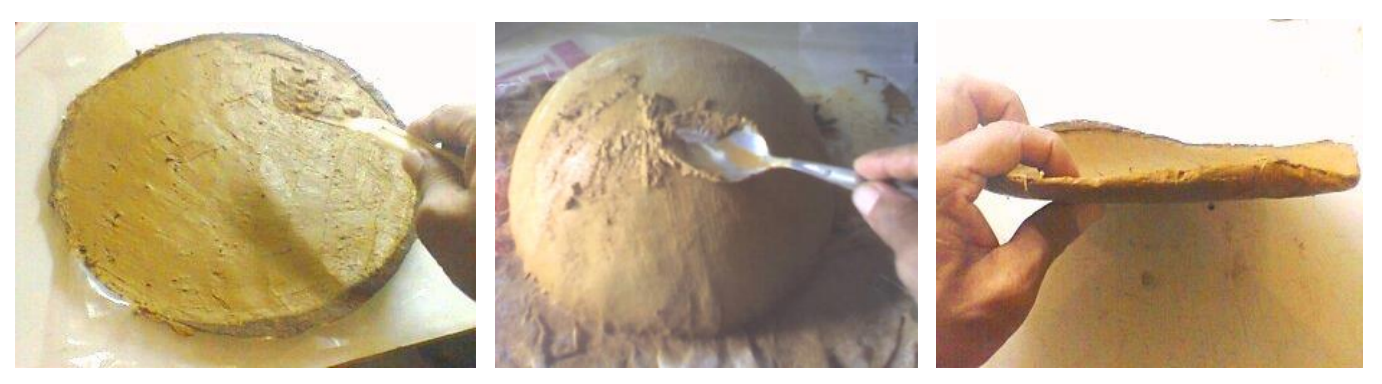

Conforme FLUSSER (2007), na gênese in-formamos - formamos dentro - a matéria segundo a nossa intenção, porém aqui a forma dada ao amorfo ajusta-se às propriedades 
do material utilizado, ou seja, o material conduz as ideias, no diálogo com a substância, ao melhor ajuste para que se atinja o objetivo desejado.

Materiais e equipamentos necessários: barro hidratado, sisal cortado com $30 \mathrm{~cm}$ de comprimento, retalhos de gaze industrial, espátula para aplicar a massa, fôrmas e plásticos para forrar as fôrmas e acondicionar o material.

Para a obtenção dos compósitos, usamos barro previamente hidratado apresentando boa consistência e um IP ${ }^{4}$ adequado para ser aplicado, ou seja, de consistência nem muito mole, nem muito dura. Em seguida, misturamos o sisal picado ao barro em quantidades muito superiores, até que a massa fique saturada e com boa liga. Para a obtenção de laminados com espessuras finas, esticamos retalhos de gaze industrial, antes e depois de esticar a massa misturada, com o auxílio de uma espátula, sempre ajustando e comprimindo a massa, ajudando a homogeneizá-la na fôrma, garantindo a espessura do laminado.

A aplicação dos laminados como revestimentos e vedações em estruturas de bambu autoportantes pode ser feita nas superfícies externas das estruturas, desde que sejam impermeabilizados contra sol, chuva e vento.

Vantagens do material em relação aos materiais convencionais: leveza e aeração, boa resistência mecânica, redução de temperatura dos ambientes, oferece diferentes possibilidades de aplicação e podem ser transportados quando as estruturas de bambu forem construídas distantes do local onde foram produzidos.

\section{Relação entre a pesquisa com compósitos laminados e o Design da Informação}

Conforme MOREIRA, (2004, CONBENGE) os tipos de estímulos absorvidos no LILD, influenciam os conceitos que fazemos dos objetos e as sensações que sentimos diante deles, contribuindo para chegarmos a momentos de ultrapassagem da dimensão lógica do objeto nos levando a um estado de criatividade. Neste ambiente a materialidade corrige o mental e viceversa, já que o ambiente contribui para criação do objeto, de acordo com as condições de luz do laboratório.

Figuras 11, 12, 13, 14 e 15: lluminação do LILD vinda do alto e dos lados que influencia a interpretação dos objetos (RAMILO, V. J. S., 2016)
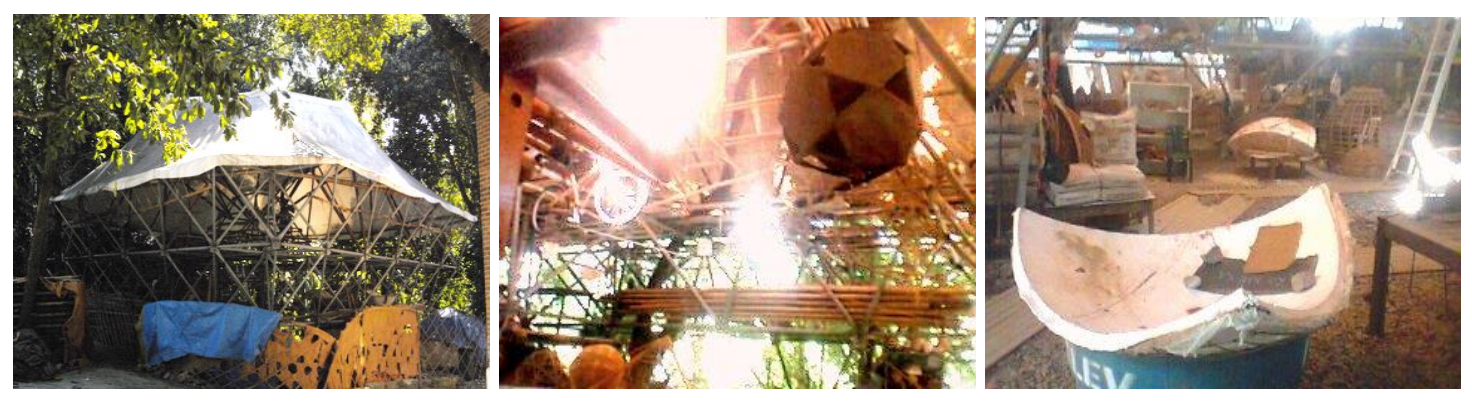

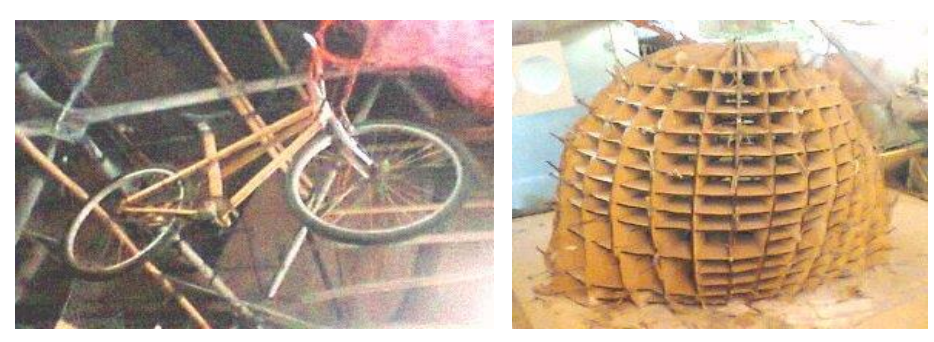

${ }^{4}$ LEME, F. B. P. (2003, p. 37) apud GHAVAMI, BARBOSA, TOLÊDO, (1997). Conforme os autores, é possível determinar índices para o solo, entre eles: Índice Plástico (IP), Limites de Liquidez (LL) e o de Plasticidade (PL). O Índice Plástico (IP) do solo é calculado pela diferença entre os de Liquidez (LL) e o de Plasticidade (PL).

De acordo com as condições do espaço, da metodologia e da técnica empregada; percebese a influência do Design da Informação ${ }^{5}$ no desenvolvimento da pesquisa, pois durante todo o processo existe o reconhecimento de uma linguagem/comunicação que irá se ocupar de informar, através de dados, códigos, símbolos, sistemas, objetos, modelos, imagens e gestos, revelando uma organização dentro de um sistema despido, a priori, de preocupações organizacionais, rústico e empírico, no qual pouco a pouco o material/objeto vai sendo construído. Em sintonia com este sistema, é possível entender essa influência e como ela se expressa, através das infinitas possibilidades de interpretações dos objetos que fazem parte do laboratório, permitindo um fluxo contínuo dessas informações, que vão se transformando em comunicação, pouco a pouco. Dessa maneira, o processo de construção e disseminação da informação se dá com a síntese das vivências e experiências nas pesquisas realizadas no laboratório e nas comunidades e também a partir das interpretações dos objetos construídos; no qual a informação é reproduzida através, de textos de livros, publicações científicas e filosóficas, apoiando-se em recursos tecnológicos, tais como o smartphone e o computador, que disponibilizam programas, vídeos e fotos na internet, por imagens de televisão, filmes, fotografias, ilustrações e vídeos; que formam o que chamamos nos dia de hoje de mídia ${ }^{6}$, seguindo a tendência da cultura atual de tecnoimagens e a partir daí transformando-se em conhecimento.

A informação flui como que para dentro de uma caixa-preta, devorando o tempo linear e congelando imagens, tal como FLUSSER se refere em seus livros: Filosofia da caixa preta (2002, [1985]) e O Mundo Codificado (2007, p.146). "Todos os textos fluirão para essa caixa (notícias e comentários teóricos sobre acontecimentos, papers científicos, poesia e especulações filosóficas) e sairão como imagens (filmes, programas de TV, fotografias)".

Figuras 16,17 e 18: Mutirão de alunos trabalhando com "Fibrobarro" no LILD e no Anil. (SANTOS, V. J., 2012)
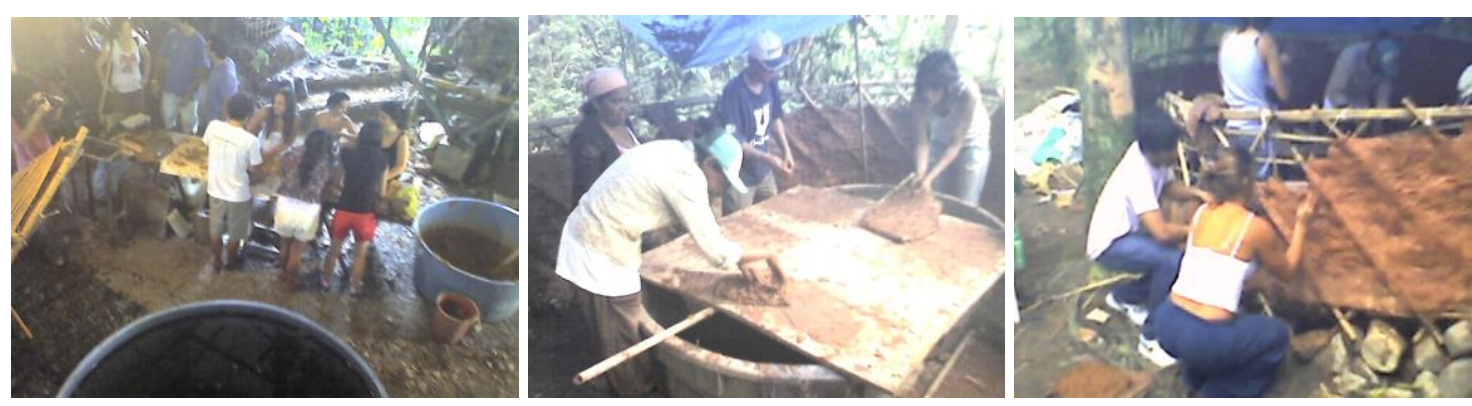
${ }^{5}$ PORTUGAL, (2013, p. 105). Área relativamente nova pertencente à área do Design Gráfico, que objetiva equacionar os aspectos sintáticos, semânticos e pragmáticos que envolvem os sistemas de informação por meio da contextualização, planejamento e produção de interface gráfica de informação para sua audiência.

${ }^{6}$ PORTUGAL, (2013). Design, educação e tecnologia, 2013. Meios eletrônicos usados para representar informações (áudio, vídeo e animação).

Figuras 19 e 20: Montagem da "Bolha" com lâminas de bambu (SANTOS, V. J., 2012)
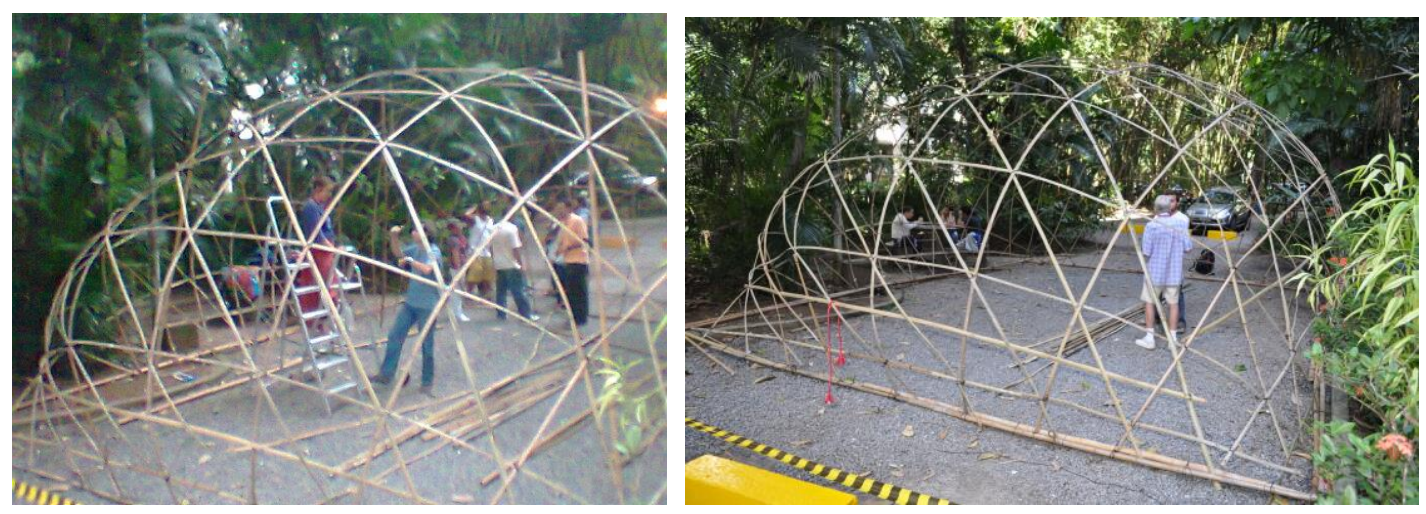

O que nos interessa aqui é desvelar a importância das leituras, interpretações e significados, que os objetos criados com os compósitos podem receber e a partir daí, observar a existência do Design da Informação se relacionando com a pesquisa, produzindo e disseminando informação e conhecimento. As diferentes leituras e pontos de vista do material nos permite apontar ajustes e desajustes. Todos nós temos diferentes modos de observar os objetos e essas observações podem ser denominadas de semânticas, quando o objeto observado nos remete a diferentes significados, conforme a leitura de cada um. Quando observamos os objetos destacando sua geometria e expressões físicas, nos referimos aos seus domínios sintáticos, conforme MOREIRA (2014, p.35). Num primeiro momento, os laminados podem ser observados, através de diferentes domínios semânticos, nos quais identificamos aspectos negativos e positivos e assim proceder às devidas correções. Neste contexto, a pragmática é um aspecto que em determinados momentos da pesquisa pode ter um significado especial, de difícil análise, pois pode apresentar uma abstração da diversidade e da multiplicidade de usos dos elementos que compõem o material/objeto, levando em consideração o modo como ele é observado e interpretado. Tomando isto como gancho e lembrando aqueles objetos, com formas e materiais diversos, que pareciam esquecidos em algum lugar do LILD, sucateados e sem função, podem ganhar um novo significado, quando vistos com um olhar diferente, pois eles ficam disponíveis para serem oportunamente utilizados, conforme MOREIRA et al (2003). Muitas vezes os objetos/modelos ficam estacionados à espera do tempo certo de serem retomados, pois a cada retomada, o objeto é visto diferentemente. 

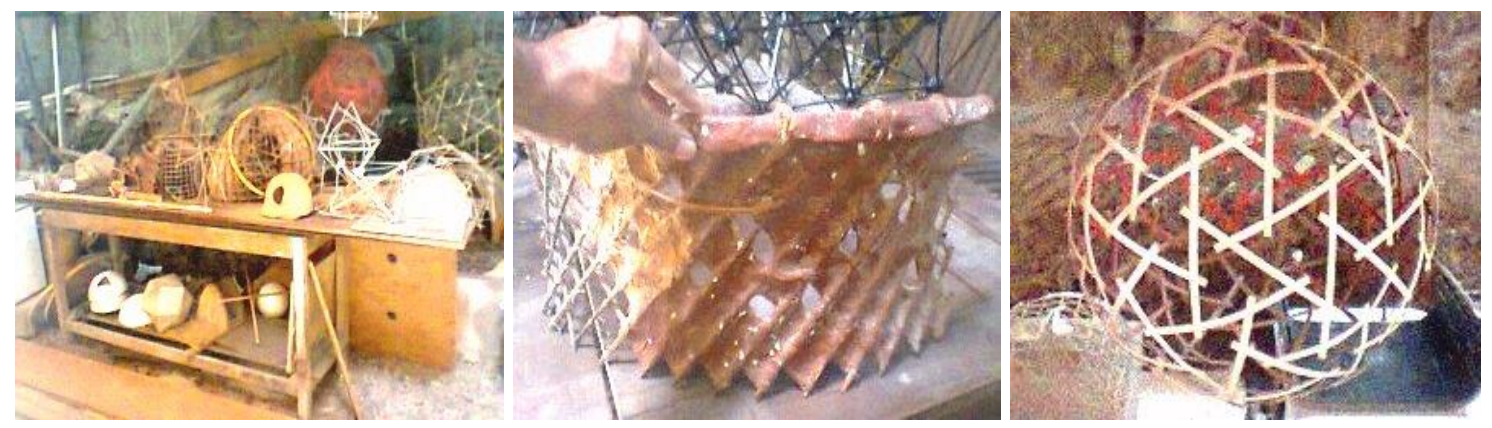

Os motivos para que isto ocorra são principalmente didáticos, pois é comum que o aprendiz priorize o tipo de material a ser utilizado; durante o desenvolvimento de um objeto, acreditando que o tipo de material seja a solução das dificuldades de concretização e funcionamento do objeto, quando na verdade a sua realização depende antes de tudo de um fator que ele ainda não domina, a técnica. Outro motivo é que ele acredita que para o bom funcionamento do objeto, a maior importância esteja no material de que ele é formado, quando na verdade a importância está na forma, ou na organização formal.

Para contornar este mal-entendido e, na maioria das vezes, para facilitar a construção de protótipos, construímos modelos com materiais variados e formas diversas. Desse modo, confrontando modelos construídos com organizações iguais e formas diferentes, verificamos do ponto de vista mecânico, a maior influência da forma (geometria) dos componentes e dos sistemas, sobre o material que a constitui. No caso dos compósitos não é diferente, pois a cada constituição a resistência mecânica de cada um é verificada, tendo em vista a possibilidade de usá-los em estrutura de bambu pré-concebida que os receberá na forma de revestimentos e vedações, ou aproveitando a resistência do material como processo construtivo.

Ao longo dos experimentos prioriza-se a sintaxe do material, visto que as insuficiências encontradas são na realidade, semântico-sintáticas, na qual a expressão ou a estruturação física; vão se ajustando constantemente na direção do seu conteúdo, semântico, ou seja, a estruturação física ou sintaxe dos compósitos é também a expressão do conteúdo semântico do pesquisador, do qual existe o cuidado para não perder o sentido da totalidade semântico-sintática dos experimentos e do sistema do qual ele faz parte. Para a gênese das formas revestidas com os laminados, nos interessa principalmente a manipulação do continuum, ou seja, os ajustes e acoplamentos sintáticos sobrepõem-se aos aspectos semânticos bastando um conjunto satisfatório de conteúdos já existentes no laboratório. Muitas vezes determinado objeto possui função e/ou funcionamento que atende aos nossos interesses e que um rápido experimento direto nos revele a utilidade de acoplamento de tal objeto - para qual poderá buscar, a posteriori, novas explicações e/ou novos significados o que explica a denominação "aproximações sucessivas", que podem ser percebidas nas transformações do objeto, que vão acontecendo pouco a pouco.

\section{Conclusão}

O conjunto de observações e interpretações nos faz perceber a existência de um Design Informacional que surge motivado pelo espaço inspirador que é o LILD e a partir dos objetos 
que fazem parte do seu acervo, se relacionando e influenciando a pesquisa, nos permitindo uma visão da mesma como um todo, onde se estuda a sua organização, objetivos, utilidades, necessidades e usuários, pressupondo o processamento de matérias-primas com o fim de se atingir um resultado. Assim, o desenvolvimento de laminados com compósitos naturais e a disseminação desse conhecimento através da informação, gera um aumento de alternativas construtivas que usam materiais alternativos, bem como oportunidade de mudança de comportamento e do nível de consciência dos usuários sobre o conceito de sustentabilidade, chamando a atenção para o uso desses materiais, mais baratos, menos poluentes e tão resistentes quanto os materiais convencionais. A pesquisa contribui ainda para a minimização da problemática habitacional, apoiando-se em uma ótica diferente da ideologia do produtivismo apoiado no capitalismo e do crescimento ilimitado, preconizando o uso de materiais naturais com baixos gastos de energia material e humana, colocando em prática, formas de relações diferentes das convencionais entre o homem e o meio, resgatando e valorizando as técnicas construtivas vernaculares, como contraposição e crítica à ideologia da fabricação de coisas vinculadas à reprodução do capital, industrialização de produtos, consumo desenfreado e descarte impensado e consequentemente à criação da cidade tradicional que tem a função de consumo, complementar à produção.

\section{Referências}

FERREIRA, Luís Manuel Rodrigues. Arquitetura de Terra: Das técnicas construtivas ao desenvolvimento de competências, Porto, Portugal, 2015.

FLUSSER, Vilém. Filosofia da caixa preta: ensaios para uma futura filosofia da fotografia. Rio de Janeiro. Relume Damará, 2002 [1985].

FLUSSER, Vilém. O Mundo codificado: por uma filosofia do design e da comunicação. Rafael Cardoso (org). Tradução: Raquel Abi-Sâmara. São Paulo: Cosac Naify, 2007.

HOGAN, Daniel (1993). Crescimento populacional e desenvolvimento sustentável. Lua Nova, São Paulo: Cedec, $n^{\circ} 31$.

ILLICH, I. (1976). A Convivencialidade. Lisboa: Publicações Europa América.

LEME, Fernando Betim Paes. Construção com "fibrosolo": um estudo de caso sobre o resgate da técnica de taipa, e seus efeitos no ambiente de clima tropical úmido com estação seca e chuvas de verão, 2003.

LOTUFO, Vitor Amaral e LOPES, João Marcos Almeida. Geodésicas e Cia, 1982, p. 56.

MORAIS, Alfredo Manuel Balacó de. Estudo do Comportamento à Compressão de Materiais Compósitos. Universidade do Porto. Tese de Doutoramento, 1997.

MOREIRA, Luís Eustáquio. Métodos de ensino de design de produtos e sua aplicação às estruturas da Engenharia Civil. CONBENGE 2004 - Congresso Brasileiro de Engenharia.

MOREIRA, Luís Eustáquio, RIPPER, José Luiz Mendes. O Jogo das Formas - Lógica do Objeto Natural. Editora Nau. Rio de Janeiro, 2014. 
PEREIRA, Daniel Augusto de Moura; PEREIRA, Mirelle Sampaio; OLIVEIRA, Raul Seixas dos Santos; MELO, Aluísio Braz e CAVALCANTE, Arthur Lacerda. Projeto de uma bioalvenaria de vedação a partir de terra crua. Revista Saúde e Ciência, On Line (2014), 3(3): 64-75, set-dez, 2014.

PORTUGAL, Cristina. Design, educação e tecnologia. Rio de Janeiro: Rio Books - 1aㅡ Edição, 2003.

RIPPER, J. L. M; LEME, F. B. P.; CORREIA de MELO, J. V. - Formas Tradicionais das Construções de Terra Versus Formas Produzidas Pelas Técnicas Contemporâneas: Uma diferente abordagem formal para a terra crua. $V$ Congresso de Arquitetura e Construção com terra no Brasil. Terra Brasil 2014.

SANTOS, Vicente Jesus dos. A técnica do "fibrobarro" armado, aplicada na construção de objetos de uso comunitário, 2012. 130 f. Pontifícia Universidade Católica do Rio de Janeiro, Departamento de Artes e Design, 2012.

SOUZA, A. E.; OlIVEIRA, G. A. F.; MIRANDA, E. R.; COUTINHO, S. G.; FILHO, G. P.; WAECHTER, H. N. - Alternativas epistemológicas para o design da informação: a forma enquanto conteúdo. Revista Brasileira de Design da Informação. São Paulo, 2016, Vol. 13, nํㅜ 2, p.107 - 118 .

XAXÁ, Mateus Soares da Silva. Construção com Terra Crua: Bloco Mattone, Universidade Federal Rural do Semi-Árido, Mossoró - RN, Monografia, 44 f., 2013.

\section{Autores}

1 - Vicente Jesus dos Santos Ramilo - Doutorando em Design, Departamento de Artes e Design da Pontifícia Universidade Católica do Rio de Janeiro - PUC - Rio - Brasil vicentejesus14@hotmail.com.br

2 - José Luiz Mendes Ripper - Professor Livre Docente, Departamento de Artes e Design da Pontifícia Universidade Católica do Rio de Janeiro - PUC - Rio - Brasil lucasripper@yahoo.com.br 